\title{
Report of a nationwide survey on actual administered radioactivities of radiopharmaceuticals for diagnostic reference levels in Japan
}

\author{
Hiroshi Watanabe ${ }^{1}$ Kazunari Ishii ${ }^{2}$ Makoto Hosono ${ }^{3}$ Etsuko Imabayashi ${ }^{4}$. \\ Koichiro Abe ${ }^{5}$ - Masayuki Inubushi' ${ }^{6}$ Kazuko Ohno ${ }^{7}$ - Yasuhiro Magata ${ }^{8}$. \\ Kinya Ono $^{9}$ - Kei Kikuchi ${ }^{10}$ - Kei Wagatsuma ${ }^{11}$ - Tadashi Takase ${ }^{12}$. \\ Kyoko Saito $^{13} \cdot$ Yasuyuki Takahashi $^{14}$
}

Received: 19 March 2016/Accepted: 20 April 2016/Published online: 6 May 2016

(C) The Japanese Society of Nuclear Medicine 2016

\begin{abstract}
Objective The optimization of medical exposure is one of the major issues regarding radiation protection in the world, and The International Committee of Radiological Protection and the International Atomic Energy Agency recommend establishing diagnostic reference levels (DRLs) as tools for dose optimization. Therefore, the development of DRLs based on the latest survey has been required for nuclear medicine-related societies and
\end{abstract}

Kazunari Ishii

ishii@med.kindai.ac.jp

1 Department of Radiological Technology, Japan Labour Health and Welfare Organization Yokohama Rosai Hospital, 3211, Kozukue, Kohoku, Yokohama, Kanagawa 222-0036, Japan

2 Department of Radiology, Kindai University Faculty of Medicine, Ohnohigashi 377-2, Osakasayama,

Osaka 589-8511, Japan

3 Institute of Advanced Clinical Medicine, Kindai University Faculty of Medicine, 377-2, Ohno-Higashi, Osakasayama, Osaka 589-8511, Japan

4 Integrative Brain Imaging Center, National Center of Neurology and Psychiatry, 4-1-1, Ogawa-Higashi, Kodaira, Tokyo 187-8551, Japan

5 Department of Diagnostic Radiology and Nuclear Medicine, Tokyo Women's Medical University, Kawada-cho 8-1, Shinjuku-ku, Tokyo 162-8666, Japan

6 Division of Nuclear Medicine, Department of Radiology, Kawasaki Medical School, 577 Matsushima, Kurashiki, Okayama 701-0192, Japan

7 Department of Radiological Technology, Kyoto College of Medical Science, 1-3 Oyamahigashimachi Sonobe-cho Nantan, Kyoto 622-0041, Japan organizations. This prompted us to conduct a nationwide survey on the actual administered radioactivity to adults for the purpose of developing DRLs in nuclear medicine.

Methods A nationwide survey was conducted from November 25, 2014 to January 16, 2015. The questionnaire was sent to all of the 1249 nuclear medicine facilities in Japan, and the responses were collected on a website using an answered form.

8 Preeminent Medical Photonics Education and Research Center, Hamamatsu University School of Medicine, 1-20-1 Handayama, Higashi-ku, Hamamatsu 431-3192, Japan

9 Department of Radiology, Kawasaki Municipal Hospital, 12-1 Shinkawadori, Kawasaki-ku, Kawasaki, Kanagawa 210-0013, Japan

10 Department of Radiology, Kitasato University Hospital, 1-15-1 Kitasato, Minami-ku, Sagamihara, Kanagawa 252-0375, Japan

11 Research Team for Neuroimaging, Tokyo Metropolitan Institute of Gerontology, 35-2, Sakae-cho, Itabashi-ku, Tokyo 173-0015, Japan

12 Department of Radiology, Showa University Hospital, 1-5-8 Hatanodai, Shinagawa-ku, Tokyo 142-8666, Japan

13 Department of Radiological Technology, Faculty of Health Sciences, Nihon Institute of Medical Science, 1276, Shimogawara, Moroyama-machi, Iruma-gun, Saitama 350-0435, Japan

14 Department of Nuclear Medicine Technology, Gunma Prefectural College of Health Sciences, 323-1 Kamioki-cho, Maebashi, Gunma 371-0052, Japan 
Results Responses were obtained from 516 facilities, for a response rate of $41 \%$. 75th percentile of ${ }^{99 \mathrm{~m}} \mathrm{Tc}-\mathrm{MDP}$ and ${ }^{99 \mathrm{~m}}$ Tc-HMDP: bone scintigraphy, ${ }^{99 \mathrm{~m}} \mathrm{Tc}-\mathrm{HM}-\mathrm{PAO},{ }^{99 \mathrm{~m}} \mathrm{Tc}-$ ECD and ${ }^{123}$ I-IMP: cerebral blood flow scintigraphy, ${ }^{99 \mathrm{~m}}$ Tc-Tetrofosmin, ${ }^{99 \mathrm{~m}} \mathrm{Tc}-\mathrm{MIBI}$ and ${ }^{201} \mathrm{Tl}-\mathrm{Cl}$; myocardial perfusion scintigraphy and ${ }^{18}$ F-FDG: oncology PET (inhouse-produced or delivery) in representative diagnostic nuclear medicine scans were 932, 937, 763, 775, 200, 831, $818,180,235$ and 252, respectively. More than $90 \%$ of the facilities were within the range of $50 \%$ from the median of these survey results in representative diagnostic nuclear medicine facilities in Japan. Responses of the administered radioactivities recommended by the package insert, texts and guidelines such as $740 \mathrm{MBq}\left({ }^{99 \mathrm{~m}} \mathrm{Tc}-\mathrm{MDP}\right.$ and ${ }^{99 \mathrm{~m}} \mathrm{Tc}-$ HMDP: bone scintigraphy), $740 \mathrm{MBq}\left({ }^{99 \mathrm{~m}} \mathrm{Tc}-\mathrm{ECD}\right.$ and 99m Tc-HM-PAO: cerebral blood flow scintigraphy) and $740 \mathrm{MBq}\left({ }^{99 \mathrm{~m}} \mathrm{Tc}-\right.$ Tetrofosmin and ${ }^{99 \mathrm{~m}}$ Tc-MIBI: myocardial perfusion scintigraphy), etc. were numerous. The administered activity of many radiopharmaceuticals of bone scintigraphy ( ${ }^{99 \mathrm{~m}} \mathrm{Tc}-\mathrm{MDP}$ and $\left.{ }^{99 \mathrm{~m}} \mathrm{Tc}-\mathrm{HMDP}\right)$, cerebral blood flow scintigraphy $\left({ }^{99 \mathrm{~m}} \mathrm{Tc}-\mathrm{HM}-\mathrm{PAO}\right)$ and myocardial perfusion scintigraphy $\left({ }^{99 \mathrm{~m}} \mathrm{Tc}\right.$-Tetrofosmin and ${ }^{99} \mathrm{~m}$ Tc-MIBI), etc. were within the range of the EU DRLs and almost none of the administered radioactivity in Japan exceeded the upper limit of SNMMI standard administered radioactivity.

Conclusions This survey indicated that the administered radioactivity in diagnostic nuclear medicine in Japan had been in the convergence zone and nuclear medicine facilities in Japan show a strong tendency to adhere to the texts and guidelines. Furthermore, the administered radioactivities in Japan were within the range of variation of the EU and the SNMMI administered radioactivities.

Keywords Survey - Diagnostic reference level · Radiopharmaceutical - Radioactivity - Optimization of dose

\section{Introduction}

The International Committee of Radiological Protection (ICRP) recommended three fundamental principles (justification, optimization of protection, and application of dose limits) for radiation protection. It should be noted that with regard to medical exposure of patients, it is not appropriate to apply dose limits or dose constraints, because such limits would often do more harm than good $[1,2]$. Therefore, the justification and optimization of protection are very important in clinical practice. However, with the development of radiation medical technology increases in the medical exposure dose are of concern. The optimization of medical exposure is one of the major issues regarding radiation protection in the world, and the ICRP and the International Atomic Energy Agency (IAEA) recommended establishing diagnostic reference levels (DRLs) as tools for dose optimization [3, 4]. In Europe, the European Union (EU) required establishment of DRLs by Council Directive 97/43/Euratom in 1996 [5]. It is suggested that DRLs should be set by countries, regions, academic societies or associations and they have been defined in Europe and North America [6-12]. On the other hand, in Japan the Japanese Society of Nuclear Medicine (JSNM) or other research groups have recommended the standard administration radioactivity dose [13, 14]. The Japan Association of Radiological Technologists (JART) recommended the reduction target dose $[15,16]$ and the JART conducted a nationwide survey of radiopharmaceutical doses [17]. Unfortunately this survey was not strictly limited to "actual" administered doses but included radioactivity doses determined by the time and date of assay of radiopharmaceuticals. Until 2015, neither a nationwide survey of "actual" administered doses had been conducted nor had DRLs been proposed by any nuclear medicine-related societies or organizations.

Concerning pediatric nuclear medicine, the European Association of Nuclear Medicine (EANM) dosage card has been proposed and developed by the Pediatric Task Group EANM in Europe [18-21] and consensus guidelines have been proposed and developed by the Society of Nuclear Medicine and Molecular Imaging (SNMMI) in North America [22-26]. In 2014, the Japanese consensus guidelines for pediatric nuclear medicine were provided by JSNM in Japan [27].

The Japan Network for Research and Information on Medical Exposures (J-RIME) was established in 2010 with the cooperation of related academic societies [28]. The J-RIME decided to establish the first DRLs (Japan DRLs) of common modality as all medical radiation-related societies and organizations at the annual meeting held in 2013. Therefore, the establishment of DRLs based on the latest survey results was required by nuclear medicine-related societies and organizations. This survey was performed voluntarily by medical radiation-related societies and organizations but was not forced by national offices.

The JSNM and JSNMT conducted a nationwide survey on the actual administered radioactivity in adults for the purpose of establishing DRL in nuclear medicine.

In Japan there is a unique system for delivered radiopharmaceuticals. When radiopharmaceuticals are provided from radiopharmaceutical manufacturers to nuclear medicine facilities, the radioactivity dose has been determined by the time and date of assay of radiopharmaceuticals. For example, in the case of ${ }^{99 \mathrm{~m}} \mathrm{Tc}$ and ${ }^{123} \mathrm{I}$ agents, the radiopharmaceutical to be delivered to the nuclear medicine facility has been assayed as the assay radioactivity 
(radioactivity at $12 \mathrm{am}$ ) of the delivery date (examination date). In addition, in the case of ${ }^{201} \mathrm{Tl}$ and ${ }^{67} \mathrm{Ga}$ agents, radioactivity in the two days after the delivery date is delivered (radioactivity at the delivery day is about 1.6 times the assay radioactivity). That is, the assay radioactivity does not actually mean the true administered radioactivity.

\section{Methods}

\section{Distribution, collection, and contents of the questionnaire}

A nationwide survey on the actual administered radioactivity of adults for the purpose of providing DRLs in nuclear medicine was conducted from November 25, 2014 to January 16, 2015. The questionnaire was sent to all 1249 facilities where nuclear medicine examinations are performed in Japan, and the responses were sent to a website.

The questionnaire included items such as the average administered radioactivity dose of an adult for each diagnostic nuclear medicine examination, number of scanners, number of staff members, number of board certified nuclear medicine physicians and nuclear medicine radiological technicians.

\section{How to calculate or evaluate the average administered radioactivity in each facility}

The average administered radioactivity was obtained from the responses following this questionnaire.

1. The average value of the actually measured doses at the administered time or the average value of the assay dose that was corrected for the administered time.

2. The average administered radioactivity per week or the average administered radioactivity of several dozen times.

3. When the administered time is set at the facility, the average dose at that time.

4. The target administered radioactivity.

5. In the case of rare nuclear medicine examinations, the average administered radioactivity for several months or 1 year, or, the administered radioactivity in standard procedures.

6. For positron emission tomography (PET), the above 2 or 3 are used as a reference. The estimated radioactivity when using an automatic injecting machine for ${ }^{18}$ F-FDG.

When calculating the average doses, responses that appeared clearly erroneous were excluded.

\section{Results and discussion}

\section{Response rate and the distribution of administered radioactivity}

Replies were obtained from 516 facilities (response rate $41 \%$ ). The average, 75th, 80th and 90th percentile of each administered radioactivity are shown in Table 1.

The 75th percentile of ${ }^{99 \mathrm{~m}} \mathrm{Tc}-\mathrm{MDP},{ }^{99 \mathrm{~m}} \mathrm{Tc}-\mathrm{HMDP}$ (bone scintigraphy), $\quad{ }^{99 \mathrm{~m}}$ Tc-HM-PAO $, \quad{ }^{99 \mathrm{~m}} \mathrm{Tc}-\mathrm{ECD}, \quad{ }^{123} \mathrm{I}-\mathrm{IMP}$ (cerebral blood flow scintigraphy), ${ }^{99 m}$ Tc-Tetrofosmin, ${ }^{99 \mathrm{~m}}$ Tc-MIBI, ${ }^{201} \mathrm{Tl}-\mathrm{Cl}$ (myocardial perfusion scintigraphy) and ${ }^{18}$ F-FDG for oncology (in-house-produced and delivery) administered radioactivity were 932, 937, 763, 775, 200, 831, 818, 180, 235 and 252, respectively.

\section{Distribution of administered radioactivity in a representative diagnostic nuclear medicine examination}

The administered radioactivity distributions of bone scintigraphy, cerebral blood flow scintigraphy, myocardial perfusion scintigraphy for single photon emission computed tomography (SPECT) and ${ }^{18} \mathrm{~F}$-fluorodeoxyglucose (FDG) tumor scintigraphy in PET are shown in Figs. 1, 2, 3, 4, 5, 6 and 7. It should be noted that in Figs. 1, 2, 4 and 6 the numbers of different response facilities are adjusted.

Figure 1 shows the administered radioactivity distribution of ${ }^{99 \mathrm{~m}}$ Tc-methylene diphosphonate (MDP) and ${ }^{99 \mathrm{~m}} \mathrm{Tc}-$ Hydroxymethylene diphosphonate (HMDP). In Japan, ${ }^{99 \mathrm{~m}}$ Tc-MDP and ${ }^{99 \mathrm{~m}}$ Tc-HMDP have been used in bone scintigraphy as radiopharmaceuticals and there are two methods of on-site preparation of kits and ready-to-use radiopharmaceuticals. Two manufacturers have provided radiopharmaceuticals for bone scintigraphy. One has 555 and $740 \mathrm{MBq}$ and the other has 370, 555, 740 and $925 \mathrm{MBq}$ as assay radioactivity for one patient. For the present survey, information regarding whether kits were prepared on-site or ready-to-use radiopharmaceuticals was not obtained. The administered radioactivity distribution of ${ }^{99 \mathrm{~m}}$ Tc-MDP and ${ }^{99 \mathrm{~m}}$ Tc-HMDP was almost the same, and, the numbers of $740 \mathrm{MBq}$ in both agents were the highest because administration of radioactivity of $555-740 \mathrm{MBq}$ is recommended by the package insert, texts and guidelines as a standard administration activity in Japan. The percentages of response rates in the range of $740 \mathrm{MBq} \pm 5 \%$ of ${ }^{99} \mathrm{~m}$ Tc-MDP and ${ }^{99}$ Tc-HMDP were 30 and $31 \%$, respectively. The latter is around $930 \mathrm{MBq}$ because the dose of $930 \mathrm{MBq}$ corresponds to the case of administration of $740 \mathrm{MBq}$ (assay activity at $12 \mathrm{am}$ ) at $10 \mathrm{am}$. Two radiopharmaceuticals for bone scintigraphy are recommended to be scanned from 2 to $3 \mathrm{~h}$ after administration. 
Table 1 Nationwide survey results and diagnostic reference levels (DRLs) in Japan

\begin{tabular}{|c|c|c|c|c|}
\hline \multirow[t]{2}{*}{ Procedure and radiopharmaceutical } & \multicolumn{3}{|c|}{$\begin{array}{l}\text { Average dosage in \% value of nationwide survey } \\
\text { results }(\mathrm{MBq})\end{array}$} & \multirow[t]{2}{*}{ DRLs $(\mathrm{MBq})^{\mathrm{a}}$} \\
\hline & $75 \%$ & $80 \%$ & $90 \%$ & \\
\hline Bone: ${ }^{99 \mathrm{~m}} \mathrm{Tc}-\mathrm{MDP}$ & 932 & 962 & 1045 & 950 \\
\hline Bone: ${ }^{99 \mathrm{~m}} \mathrm{Tc}-\mathrm{HMDP}$ & 937 & 963 & 1045 & 950 \\
\hline Bone marrow: ${ }^{111} \mathrm{I} n-\mathrm{Cl}$ & 125 & 125 & 125 & 120 \\
\hline Cerebral blood flow: ${ }^{99 \mathrm{~m}} \mathrm{Tc}-\mathrm{HM}-\mathrm{PAO}$ (rest or stress) & 763 & 800 & 932 & 800 \\
\hline Cerebral blood flow: ${ }^{99 \mathrm{~m}} \mathrm{Tc}-\mathrm{HM}-\mathrm{PAO}$ (rest and stress) & 1155 & 1280 & 1464 & 1200 \\
\hline Cerebral blood flow: ${ }^{99 \mathrm{~m}} \mathrm{Tc}-\mathrm{ECD}$ (rest or stress) & 775 & 800 & 848 & 800 \\
\hline Cerebral blood flow: ${ }^{99 \mathrm{~m}} \mathrm{Tc}-\mathrm{ECD}$ (rest and stress) & 1007 & 1068 & 1130 & 1100 \\
\hline Cerebral blood flow: ${ }^{123}$ I-IMP (rest or stress) & 200 & 211 & 236 & 200 \\
\hline Cerebral blood flow: ${ }^{123} \mathrm{I}$-IMP (rest and stress) & 287 & 310 & 340 & 300 \\
\hline Cerebral blood flow: Iomazenil $\left({ }^{123} \mathrm{I}\right)$ & 193 & 195 & 244 & 200 \\
\hline Dopamine transporter: Ioflupane $\left({ }^{123} \mathrm{I}\right)$ & 186 & 189 & 195 & 190 \\
\hline Cisternography: ${ }^{111}$ I $n$-DTPA & 63 & 63 & 72 & 70 \\
\hline Thyroid imaging: ${ }^{123} \mathrm{I}-\mathrm{NaI}$ & 9 & 9 & 13 & 10 \\
\hline Thyroid imaging: ${ }^{99 \mathrm{~m}} \mathrm{Tc}-$ pertechnetate & 261 & 370 & 370 & 300 \\
\hline Parathyroid: ${ }^{201} \mathrm{Tl}-\mathrm{Cl}$ & 120 & 120 & 175 & 120 \\
\hline Parathyroid: ${ }^{99 \mathrm{~m}} \mathrm{Tc}$-pertechnetate & 300 & 370 & 391 & 300 \\
\hline Parathyroid: ${ }^{99 \mathrm{~m}} \mathrm{Tc}-\mathrm{MIBI}$ & 784 & 824 & 848 & 800 \\
\hline Lung ventilation: ${ }^{81 \mathrm{~m}}$ Kgas & 185 & 185 & 288 & 200 \\
\hline Lung ventilation: ${ }^{133} \mathrm{Xe}$ gas & 468 & 480 & 489 & 480 \\
\hline Lung perfusion: ${ }^{99 \mathrm{~m}} \mathrm{Tc}-\mathrm{MAA}$ & 260 & 261 & 370 & 260 \\
\hline Venography: ${ }^{99 \mathrm{~m}} \mathrm{Tc}-\mathrm{MAA}$ & 459 & 555 & 740 & 500 \\
\hline Liver and spleen: ${ }^{99 \mathrm{~m}} \mathrm{Tc}$-phytate & 185 & 197 & 228 & 200 \\
\hline Liver function: ${ }^{99 \mathrm{~m}} \mathrm{Tc}-\mathrm{GSA}$ & 251 & 260 & 261 & 260 \\
\hline Hepatobiliary: ${ }^{99 \mathrm{~m}} \mathrm{Tc}-\mathrm{PMT}$ & 252 & 260 & 261 & 260 \\
\hline Liver and spleen: ${ }^{99 \mathrm{~m}} \mathrm{Tc}-\mathrm{Sn}$ colloid & 157 & 185 & 185 & 180 \\
\hline Myocardial perfusion: ${ }^{201} \mathrm{Tl}-\mathrm{Cl}$ & 180 & 180 & 196 & 180 \\
\hline Myocardial perfusion: ${ }^{99 \mathrm{~m}} \mathrm{Tc}$-tetrofosmin (rest or stress) & 831 & 880 & 951 & 900 \\
\hline Myocardial perfusion: ${ }^{99 \mathrm{~m}} \mathrm{Tc}$-tetrofosmin (rest and stress) & 1110 & 1130 & 1247 & 1200 \\
\hline Myocardial perfusion: ${ }^{99 \mathrm{~m}} \mathrm{Tc}-\mathrm{MIBI}$ (rest or stress) & 818 & 848 & 900 & 900 \\
\hline Myocardial perfusion: ${ }^{99 \mathrm{~m}} \mathrm{Tc}-\mathrm{MIBI}$ (rest and stress) & 1110 & 1125 & 1221 & 1200 \\
\hline Myocardial fatty acid metabolism: ${ }^{123}$ I-BMIPP & 130 & 130 & 159 & 130 \\
\hline Cardiac sympathetic nerve imaging: ${ }^{123} \mathrm{I}-\mathrm{MIBG}$ & 129 & 130 & 130 & 130 \\
\hline Cardiac blood pool: ${ }^{99 \mathrm{~m}} \mathrm{Tc}-\mathrm{HSA}$ & 931 & 932 & 1045 & 1000 \\
\hline Cardiac blood pool: ${ }^{99 \mathrm{~m}}$ Tc-HSA-D & 944 & 997 & 1045 & 1000 \\
\hline Myocardial infarction: ${ }^{99 \mathrm{~m}} \mathrm{Tc}-\mathrm{PYP}$ & 750 & 925 & 1001 & 800 \\
\hline Salivary gland: ${ }^{99 \mathrm{~m}} \mathrm{Tc}-$ pertechnetate & 370 & 370 & 466 & 370 \\
\hline Meckel's diverticulum: ${ }^{99 \mathrm{~m}} \mathrm{Tc}$-pertechnetate & 466 & 523 & 740 & 500 \\
\hline Gastrointestinal bleeding: ${ }^{99 \mathrm{~m}} \mathrm{Tc}-\mathrm{HSA}-\mathrm{D}$ & 1036 & 1045 & 1046 & 1040 \\
\hline Renal imaging (static): ${ }^{99 \mathrm{~m}} \mathrm{Tc}-\mathrm{DMSA}$ & 210 & 230 & 261 & 210 \\
\hline Renal imaging (dynamic): ${ }^{99 \mathrm{~m}} \mathrm{Tc}-\mathrm{MAG} 3$ & 390 & 400 & 424 & 400 \\
\hline Renal imaging (dynamic): 99mTc-DTPA & 380 & 400 & 502 & 400 \\
\hline Adrenal cortex: ${ }^{131}$ I-Adosterol & 44 & 44 & 44 & 44 \\
\hline Adrenal medulla: ${ }^{131} \mathrm{I}-\mathrm{MIBG}$ & 40 & 40 & 48 & 45 \\
\hline Adrenal medulla: ${ }^{123} \mathrm{I}-\mathrm{MIBG}$ & 130 & 130 & 170 & 130 \\
\hline Tumor: ${ }^{201} \mathrm{Tl}-\mathrm{Cl}$ & 178 & 180 & 180 & 180 \\
\hline Tumor and inflammation: ${ }^{67} \mathrm{Ga}$-citrate & 174 & 174 & 208 & 200 \\
\hline
\end{tabular}


Table 1 continued

\begin{tabular}{|c|c|c|c|c|}
\hline \multirow[t]{2}{*}{ Procedure and radiopharmaceutical } & \multicolumn{3}{|c|}{$\begin{array}{l}\text { Average dosage in \% value of nationwide survey } \\
\text { results }(\mathrm{MBq})\end{array}$} & \multirow[t]{2}{*}{ DRLs $(\mathrm{MBq})^{\mathrm{a}}$} \\
\hline & $75 \%$ & $80 \%$ & $90 \%$ & \\
\hline Lymphatic system: ${ }^{99 \mathrm{~m}} \mathrm{Tc}-\mathrm{HSA}-\mathrm{D}$ (not covered with health insurance) & 928 & 932 & 1045 & 950 \\
\hline Sentinel lymph node: ${ }^{99 \mathrm{~m}} \mathrm{Tc}$ colloid & 111 & 111 & 156 & 120 \\
\hline Sentinel lymph node: ${ }^{99 \mathrm{~m}} \mathrm{Tc}-$ phytate & 93 & 105 & 127 & 120 \\
\hline RI angiography: ${ }^{99 m}$ Tc-HSA-D & 943 & 987 & 1046 & 1000 \\
\hline Tumor: ${ }^{18}$ F-FDG (in-house-produced) & 235 & 240 & 260 & 240 \\
\hline Tumor: ${ }^{18}$ F-FDG (delivery) & 252 & 260 & 280 & 240 \\
\hline Brain: ${ }^{18}$ F-FDG (in-house-produced) & 227 & 233 & 248 & 240 \\
\hline Brain: ${ }^{18}$ F-FDG (delivery) & 255 & 259 & 295 & 240 \\
\hline${ }^{15} \mathrm{O}-\mathrm{CO}_{2}$ gas: $2 \mathrm{D}$ & 7500 & 7700 & 8100 & 8000 \\
\hline${ }^{15} \mathrm{O}-\mathrm{O}_{2}$ gas: $2 \mathrm{D}$ & 4500 & 5400 & 8360 & 6000 \\
\hline${ }^{15} \mathrm{O}-\mathrm{CO}$ gas: $2 \mathrm{D}$ & 3000 & 3000 & 3800 & 3000 \\
\hline${ }^{15} \mathrm{O}-\mathrm{CO}_{2}$ gas: $3 \mathrm{D}$ & 2888 & 2910 & 2955 & 2900 \\
\hline${ }^{15} \mathrm{O}-\mathrm{O}_{2}$ gas: $3 \mathrm{D}$ & 6600 & 7300 & 7400 & 7000 \\
\hline${ }^{15} \mathrm{O}-\mathrm{CO}$ gas: 3D & 7125 & 7500 & 7750 & 7500 \\
\hline Myocardial metabolism: ${ }^{18} \mathrm{~F}-\mathrm{FDG}$ (in-house-produced) & 221 & 223 & 236 & 240 \\
\hline Myocardial metabolism: ${ }^{18}$ F-FDG (delivery) & 251 & 258 & 287 & 240 \\
\hline Myocardial perfusion: ${ }^{13} \mathrm{~N}-\mathrm{NH}_{3}$ & 718 & - & 740 & 720 \\
\hline
\end{tabular}

a Adult dosage (MBq)

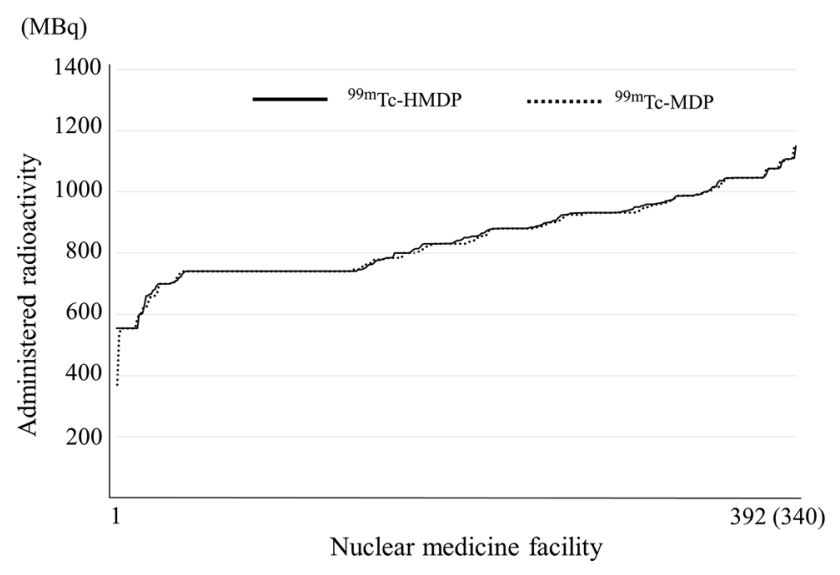

Fig. 1 Bone: ${ }^{99 \mathrm{~m}}$ Tc-HMDP and ${ }^{99 \mathrm{~m}} \mathrm{Tc}-\mathrm{MDP}$. Note: They are arranged in decreasing order to separate the nuclear medicine facilities with more from those with less radioactivity. Numbers responding for ${ }^{99 \mathrm{~m}} \mathrm{Tc}$ HMDP and ${ }^{99 m}$ Tc-MDP were 392 and 340, respectively

This may reflect the reality that many nuclear facilities are imaging at $1 \mathrm{pm}$ after administration at 10 am using an assay radioactivity of $740 \mathrm{MBq}$ (ready-to-use radiopharmaceuticals).

Figure 2 shows the distribution of ${ }^{99 \mathrm{~m}} \mathrm{Tc}$-hexamethylpropylene amine oxime (HM-PAO) and ${ }^{99 \mathrm{~m}} \mathrm{Tc}$-ethyl

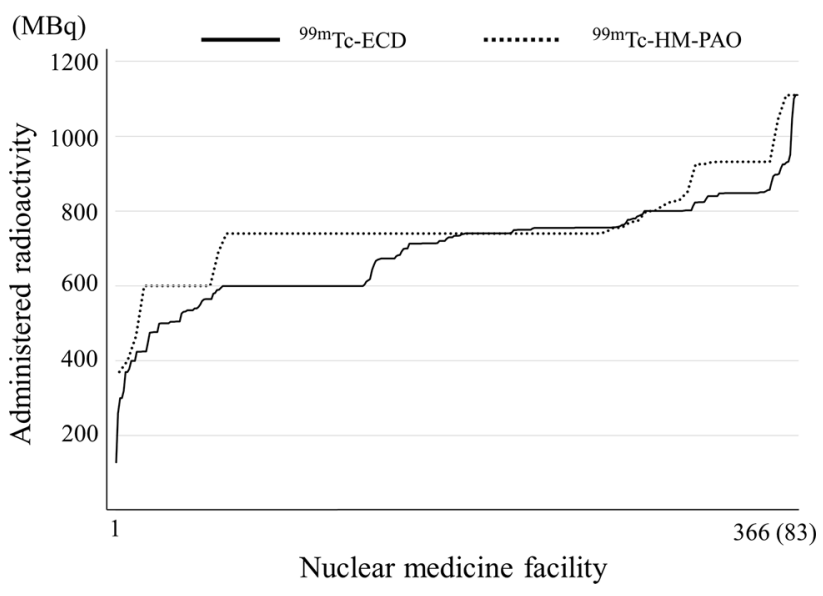

Fig. 2 Cerebral blood flow: ${ }^{99 \mathrm{~m}} \mathrm{Tc}-\mathrm{ECD}$ and ${ }^{99 \mathrm{~m}} \mathrm{Tc}-\mathrm{HM}-\mathrm{PAO}$. Note: They are arranged in decreasing order to separate the nuclear medicine facilities with more from those with less radioactivity. Numbers responding for ${ }^{99 \mathrm{~m}} \mathrm{Tc}-\mathrm{ECD}$ and ${ }^{99 \mathrm{~m}} \mathrm{Tc}-\mathrm{HM}-\mathrm{PAO}$ were 366 and 83 , respectively

cysteinate dimer (ECD). In Japan, ${ }^{99 \mathrm{~m}} \mathrm{Tc}-\mathrm{HM}-\mathrm{PAO}$ and ${ }^{99 \mathrm{~m}} \mathrm{Tc}-\mathrm{ECD}$ are used for cerebral blood flow scintigraphy of ${ }^{99 \mathrm{~m}} \mathrm{Tc}$ agents as a radiopharmaceutical. ${ }^{99 \mathrm{~m}} \mathrm{Tc}-\mathrm{HM}-\mathrm{PAO}$ is used only by on-site preparation of kits and ${ }^{99 \mathrm{~m}} \mathrm{Tc}-\mathrm{ECD}$ either by on-site preparation of kits or ready-to-use 


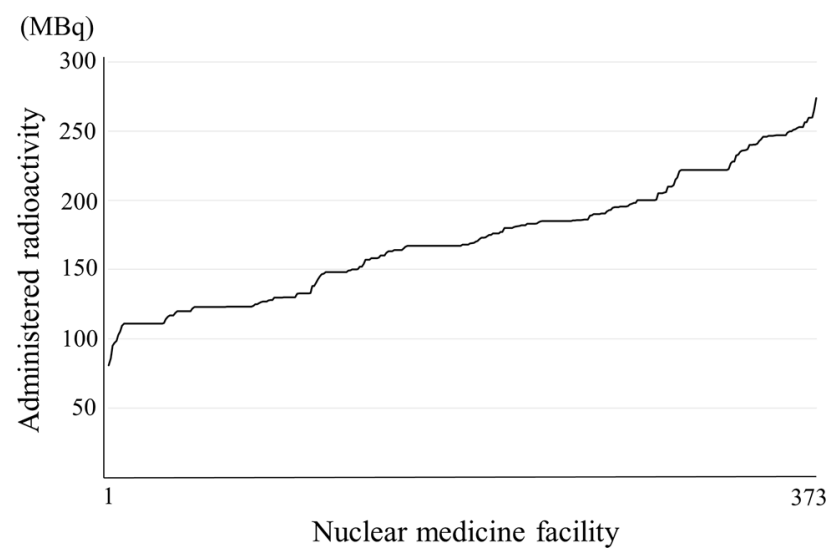

Fig. 3 Cerebral blood flow: ${ }^{123}$ I-IMP. Note: They are arranged in decreasing order to separate the nuclear medicine facilities with more from those with less radioactivity. Number responding was 373

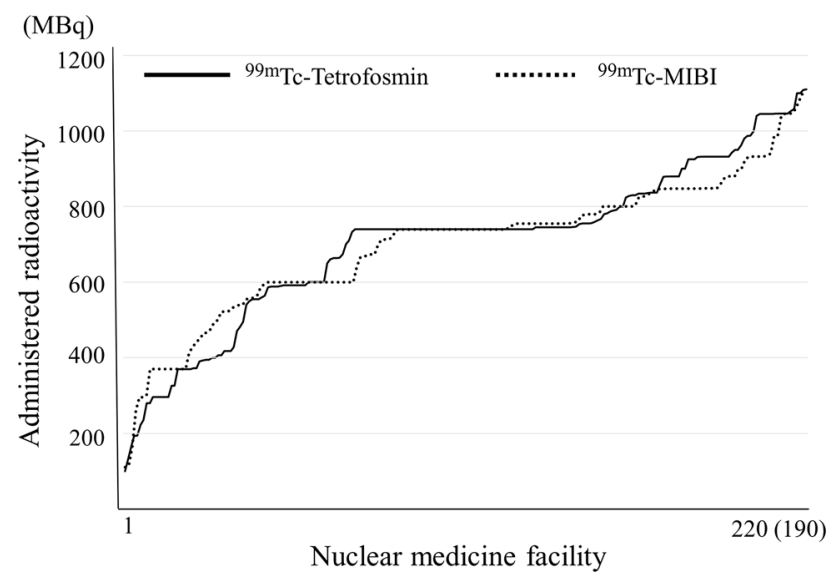

Fig. 4 Myocardial perfusion: ${ }^{99 \mathrm{~m}} \mathrm{Tc}-$ Tetrofosmin and ${ }^{99 \mathrm{~m}} \mathrm{Tc}-\mathrm{MIBI}$. Note: They are arranged in decreasing order to separate the nuclear medicine facilities with more from those with less radioactivity. Numbers responding for ${ }^{99 \mathrm{~m}}$ Tc-Tetrofosmin and ${ }^{99 \mathrm{~m}}$ Tc-MIBI were 220 and 190 , respectively

radiopharmaceuticals. The assay radioactivities of ${ }^{99 \mathrm{~m}} \mathrm{Tc}-$ ECD are 400 and $600 \mathrm{MBq}$ for one patient. Concerning ${ }^{99 \mathrm{~m}} \mathrm{Tc}-\mathrm{HM}-\mathrm{PAO}$, the number of the responses of $740 \mathrm{MBq}$ was the highest because administration radioactivity of $370-740 \mathrm{MBq}$ is recommended by the package insert, texts and guidelines as a standard administration radioactivity in Japan. For ${ }^{99 \mathrm{~m}} \mathrm{Tc}-\mathrm{ECD}$, the number of responses of around $740 \mathrm{MBq}$ was the most because an administration dose of around $370-740 \mathrm{MBq}$ is highest by the package insert, texts and guidelines as a standard administration dose as well as ${ }^{99 \mathrm{~m}} \mathrm{Tc}-\mathrm{ECD}$. The percentages of response rates in the range of $740 \mathrm{MBq} \pm 5 \%$ of ${ }^{99 \mathrm{~m}} \mathrm{Tc}-\mathrm{HM}-\mathrm{PAO}$ and ${ }^{99 \mathrm{~m}}$ Tc-ECD were 61 and $33 \%$, respectively.

Figure 3 shows the results of the distribution of $\mathrm{N}$-isopropyl- $p-\left[{ }^{123} \mathrm{I}\right]$ iodoamphetamine (IMP). In Japan, for cerebral blood flow scintigraphy ${ }^{123}$ I-IMP is provided by

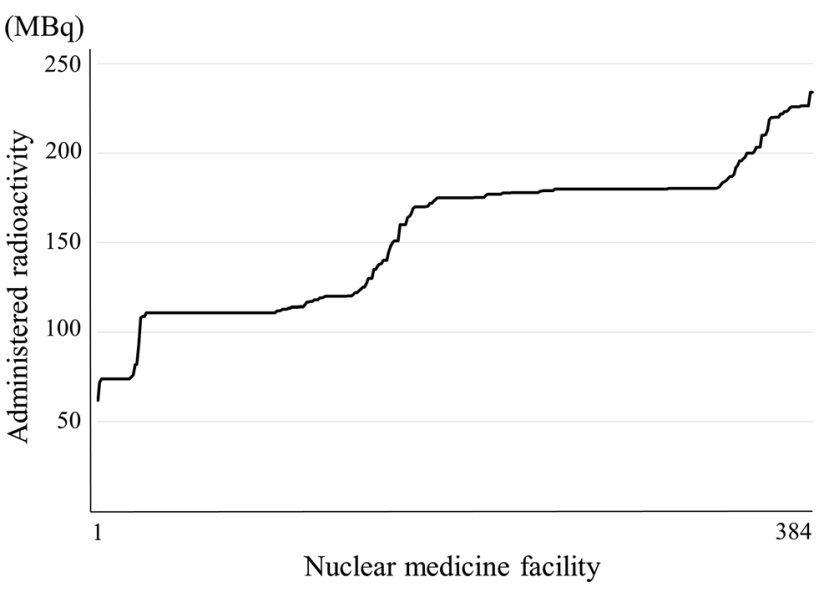

Fig. 5 Myocardial perfusion: ${ }^{201} \mathrm{Tl}-\mathrm{Cl}$. Note: They are arranged in decreasing order to separate the nuclear medicine facilities with more from those with less radioactivity. Number responding was 384

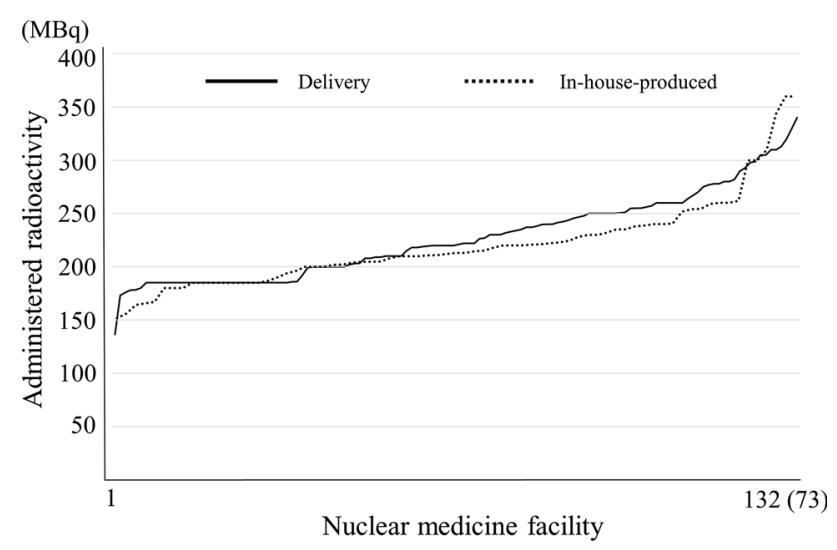

Fig. 6 Tumor: ${ }^{18}$ F-FDG. Note: They are arranged in decreasing order to separate the nuclear medicine facility with more from those with less radioactivity. Numbers of delivery and in-house-produced were 132 and 73 , respectively

only delivery. ${ }^{123}$ I-IMP has more kinds of assay radioactivities than other radiopharmaceuticals. One manufacturer has $111,148,167,185$ and $222 \mathrm{MBq}$ and another has 111, 167 and $222 \mathrm{MBq}$ as assay radioactivity for one patient. In addition, for ${ }^{123} \mathrm{I}$-IMP, a wide range of administration doses of $111-222 \mathrm{MBq}$ is recommended by the package insert, texts and guidelines as a standard administration dose. In particular, a wide range of administration radioactivity $(37-222 \mathrm{MBq})$ is recommended in the package insert. Thus, the distribution of radioactivity of ${ }^{123} \mathrm{I}$ IMP is scattered, which may reflect the various uses to which it is put at individual facilities. The response rate in the range of $111 \mathrm{MBq} \pm 5 \%$ of ${ }^{123} \mathrm{I}$-IMP was $7 \%$.

Figure 4 shows the distribution of ${ }^{99 \mathrm{~m}} \mathrm{Tc}$-Tetrofosmin and ${ }^{99 \mathrm{~m}} \mathrm{Tc}$-hexakis-2-methoxyisobutylisonitrile (MIBI). In Japan, ${ }^{99 \mathrm{~m}} \mathrm{Tc}$-Tetrofosmin and ${ }^{99 \mathrm{~m}} \mathrm{Tc}-\mathrm{MIBI}$ have been used for myocardial perfusion scintigraphy as ${ }^{99 \mathrm{~m}} \mathrm{Tc}$ agents, and, 


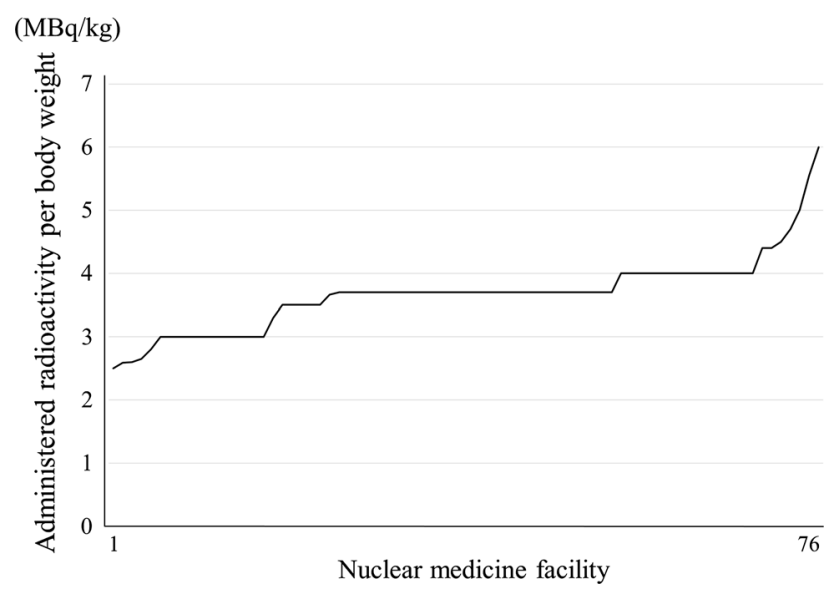

Fig. 7 Tumor: ${ }^{18}$ F-FDG, administered activity per body weight. Note: They are arranged in decreasing order to separate the nuclear medicine facilities with more from those with less radioactivity. Number responding was 76

both agents have two methods of on-site preparation of kits and ready-to-use radiopharmaceuticals. ${ }^{99 \mathrm{~m}} \mathrm{Tc}$-Tetrofosmin has 296, 592 and $740 \mathrm{MBq}$ and ${ }^{99 \mathrm{~m}} \mathrm{Tc}-\mathrm{MIBI}$ has 370,600 and $740 \mathrm{MBq}$ for one patient as the assay radioactivity. The response of around $740 \mathrm{MBq}$ was the most common because an administration dose of $370-740 \mathrm{MBq}$ is recommended by the package insert, texts and guidelines as a standard administration dose. The response rates in the range of $740 \mathrm{MBq} \pm 5 \%$ of ${ }^{99 \mathrm{~m}} \mathrm{Tc}-$ Tetrofosmin and ${ }^{99 \mathrm{~m}} \mathrm{Tc}-\mathrm{MIBI}$ were 37 and $30 \%$, respectively.

Figure 5 shows the distribution of ${ }^{201} \mathrm{Tl}-\mathrm{Cl}$. In Japan, ${ }^{201} \mathrm{Tl}-\mathrm{Cl}$ for myocardial perfusion scintigraphy has been made available only by delivery. The assay radioactivities of ${ }^{201} \mathrm{Tl}-\mathrm{Cl}$ are $74,11,148 \mathrm{MBq}$ for one patient provided by two manufacturers. The responses of 111 and $180 \mathrm{MBq}$ were the most common. In Japan the manufacturers usually provide ${ }^{201} \mathrm{Tl}-\mathrm{Cl}$ to the nuclear medicine facility within 2 days before the assay date; therefore, $180 \mathrm{MBq}$ corresponds to the radioactivity 2 days before the assay radioactivity $111 \mathrm{MBq}$. The administration radioactivity of around $74-111 \mathrm{MBq}$ is recommended by the package insert, texts and guidelines as a standard administration activity for ${ }^{201} \mathrm{Tl}-\mathrm{Cl}$. This study indicated that many nuclear medicine facilities administered the assay radioactivity $111 \mathrm{MBq}$ for one patient in Japan (actual administered radioactivity is $180 \mathrm{MBq}$ ). The response rate in the range of $180 \mathrm{MBq} \pm 5 \%$ of ${ }^{201} \mathrm{Tl}-\mathrm{Cl}$ was $43 \%$.

The distribution of administered radioactivity for ${ }^{18} \mathrm{~F}$ FDG oncology PET is shown in Fig. 6 and the responses of $185 \mathrm{MBq}$ were the greatest. In Japan, nuclear medicine facilities have two methods, in-housed-produced and delivery for ${ }^{18}$ F-FDG oncology PET. Provided manufacture of ${ }^{18} \mathrm{~F}-\mathrm{FDG}$ is one and it has an assay radioactivity of only $185 \mathrm{MBq}$ for one patient. For these reasons, it is presumed that the responses of $185 \mathrm{MBq}$ were diverse. The response rate in the range of $185 \mathrm{MBq} \pm 5 \%$ of ${ }^{18} \mathrm{~F}-\mathrm{FDG}$ in-housed-produced and delivery were 19 and $27 \%$, respectively. In addition, the administered radioactivity per body weight $(\mathrm{MBq} / \mathrm{kg}$ ) was also investigated (Fig. 7). However, whether in-housed-produced or delivery was not distinguished by the survey items. An administered radioactivity per body weight of $2-5 \mathrm{MBq} / \mathrm{kg}$ (three dimensional collection) is recommended by the guidelines [29] and it was found that most of the facilities administered within the recommended radioactivity doses per body weight. Furthermore, the numbers of responses of 3.0, 3.7 and $4.0 \mathrm{MBq} / \mathrm{kg}$ were the highest, and the administered radioactivity dose per body weight was considered is be determined in accordance with the guidelines.

This survey reveals that many nuclear facilities determined the administered radioactivity dose according to the package insert, texts and guidelines.

\section{Comparison with EU and North America}

Basically DRLs are determined based on 75th percentile of the survey results. To compare the administered radioactivity between Japan and EU, a summary of Japanese and EU DRLs for diagnostic nuclear medicine is shown in Table 2 following a list of the EU DRLs [9]. Many DRL doses of radiopharmaceuticals: bone scintigraphy $\left({ }^{99 \mathrm{~m}} \mathrm{Tc}-\right.$ MDP and ${ }^{99 m}$ Tc-HMDP), cerebral blood flow scintigraphy $\left({ }^{99 \mathrm{~m}} \mathrm{Tc}-\mathrm{HM}-\mathrm{PAO}\right)$ and myocardial perfusion scintigraphy $\left({ }^{99 \mathrm{~m}} \mathrm{Tc}-\right.$ Tetrofosmin and $\left.{ }^{99 \mathrm{~m}} \mathrm{Tc}-\mathrm{MIBI}\right)$, etc. were within the range of the EU DRLs. Concerning ${ }^{201} \mathrm{Tl}-\mathrm{Cl}$ (myocardial perfusion scintigraphy), Japan DRL $180 \mathrm{MBq}$ exceeds the range of the EU DRL (75-150 MBq). For ${ }^{99 \mathrm{~m}} \mathrm{Tc}$-pertechnetate (thyroid scintigraphy), Japan DRL $300 \mathrm{MBq}$ exceeded the range of the EU DRLs (75-222 MBq). However, in the ${ }^{18} \mathrm{~F}$-FDG for oncology PET and ${ }^{123} \mathrm{I}-\mathrm{NaI}$ for thyroid scintigraphy, Japan DRLs were at the lowest level in the range of the EU DRLs. These variations reflect the situation of each country, and so it is not considered that Japan DRLs are particularly high as compared with those of EU. Next, the results of this study were compared with SNMMI standard administered radioactivity in representative diagnostic nuclear medicine procedures: the upper limit of SNMMI standard administration radioactivity (bone scintigraphy: $1110 \mathrm{MBq}$ [30], cerebral blood flow scintigraphy: $1110 \mathrm{MBq}$ [31], myocardial perfusion ${ }^{99 \mathrm{~m}} \mathrm{Tc}$ agents: $1110 \mathrm{MBq},{ }^{201} \mathrm{Tl}-\mathrm{Cl}: 148 \mathrm{MBq}$ [32], ${ }^{18} \mathrm{~F}-$ FDG oncology PET: $740 \mathrm{MBq}$ [33]) following facilities were bone scintigraphy $\left({ }^{99 \mathrm{~m}}\right.$ Tc-MDP: $99.4 \%,{ }^{99 \mathrm{~m}} \mathrm{Tc}-$ HMDP: $99.7 \%)$, cerebral blood flow scintigraphy $\left({ }^{99 \mathrm{~m}} \mathrm{Tc}-\right.$ HM-PAO: $100 \%,{ }^{99 \mathrm{~m}} \mathrm{Tc}-\mathrm{ECD}: 100 \%$ ), myocardial perfusion $\left({ }^{99 \mathrm{~m}} \mathrm{Tc}-T e t r o f o s m i n: 100 \%,{ }^{99 \mathrm{~m}} \mathrm{Tc}-\mathrm{MIBI}: 100 \%\right.$, ${ }^{201} \mathrm{Tl}-\mathrm{Cl}$ : $\left.41 \%\right)$ and oncology PET $\left({ }^{18} \mathrm{~F}-\mathrm{FDG}\right.$ of both in- 
Table 2 Comparisons of diagnostic reference levels (DRLs) between European Union (EU) and Japan

\begin{tabular}{|c|c|c|c|}
\hline \multirow[t]{2}{*}{ Procedure and radiopharmaceutical } & \multicolumn{2}{|l|}{ DRLs in $\mathrm{EU}^{\mathrm{a}}(\mathrm{MBq})$} & \multirow[t]{2}{*}{ DRLs in Japan $(\mathrm{MBq})$} \\
\hline & Most common value & Range & \\
\hline Bone: ${ }^{99 \mathrm{~m}} \mathrm{Tc}-\mathrm{MDP}$ and HMDP & 600 & $500-1110$ & 950 \\
\hline Myocardial perfusion: ${ }^{201} \mathrm{Tl}-\mathrm{Cl}$ & 110 & $75-150$ & 180 \\
\hline Myocardial perfusion: ${ }^{99 \mathrm{~m}} \mathrm{Tc}$-tetrofosmin (rest or stress) & 1200 & $300-1500$ & 900 \\
\hline Myocardial perfusion: ${ }^{99 \mathrm{~m}} \mathrm{Tc}-\mathrm{MIBI}$ (rest or stress) & 1200 & $300-1480$ & 900 \\
\hline Tumor: ${ }^{18}$ F-FDG (in-housed-produced and delivery) & - & $200-400$ & 240 \\
\hline Thyroid: ${ }^{99 \mathrm{~m}}$ Tc-pertechnetate & 80 & $75-222$ & 300 \\
\hline Thyroid: ${ }^{123} \mathrm{I}-\mathrm{NaI}$ & 20 & $10-37$ & 10 \\
\hline Lung perfusion: ${ }^{99 \mathrm{~m}} \mathrm{Tc}-\mathrm{MAA}$ & 150 & $100-296$ & 260 \\
\hline Renal imaging (static): ${ }^{99 \mathrm{~m}} \mathrm{Tc}-\mathrm{DMSA}$ & - & $70-183$ & 210 \\
\hline Renal imaging (dynamic): ${ }^{99 m} \mathrm{Tc}-\mathrm{MAG} 3$ & 100 & $100-370$ & 400 \\
\hline Renal imaging (dynamic): ${ }^{99 \mathrm{~m}} \mathrm{Tc}-\mathrm{DTPA}$ & - & $150-540$ & 400 \\
\hline Parathyroid: ${ }^{99 \mathrm{~m}} \mathrm{Tc}-\mathrm{MIBI}$ & - & $400-900$ & 800 \\
\hline Cerebral blood flow: ${ }^{99 \mathrm{~m}} \mathrm{Tc}-\mathrm{HM}-\mathrm{PAO}$ (rest or stress) & 500 & $500-1110$ & 800 \\
\hline Tumor and inflammation: ${ }^{67} \mathrm{Ga}$-citrate & - & $110-370$ & 200 \\
\hline
\end{tabular}

${ }^{a}$ European Commission, 2010, DDM2 project report part 2: diagnostic reference levels (DRLs) in Europe

housed-produced and delivery: 100\%), respectively. Almost none of the administered radioactivity doses in Japan exceeded the upper limit of SNMMI standard administration radioactivity except for ${ }^{201} \mathrm{Tl}-\mathrm{Cl}$ for myocardial perfusion. In ${ }^{18} \mathrm{~F}-\mathrm{FDG}$ for oncology PET, none of the doses at any of the facilities $(100 \%)$ exceeded the lower limit of SNMMI recommended administered radioactivity.

\section{Convergence rate of the administered radioactivity, and the role of academic societies and experts}

Table 3 shows the percentage of facilities that were within the range $(25,30$ and $50 \%)$ from the median of

Table 3 Range from median value in this study results of representative administered radiopharmaceuticals

\begin{tabular}{l}
\hline Procedure and radiopharmaceutical \\
\hline Bone: ${ }^{99 \mathrm{~m}} \mathrm{Tc}-\mathrm{MDP}$ \\
Bone: ${ }^{99 \mathrm{~m}} \mathrm{Tc}-\mathrm{HMDP}$ \\
Cerebral blood flow: ${ }^{99 \mathrm{~m}} \mathrm{Tc}-\mathrm{HM}-\mathrm{PAO}$ \\
Cerebral blood flow: ${ }^{99 \mathrm{~m}} \mathrm{Tc}-\mathrm{ECD}$ \\
Cerebral blood flow: ${ }^{123} \mathrm{I}-\mathrm{IMP}$ \\
Myocardial perfusion: ${ }^{99 \mathrm{~m}} \mathrm{Tc}-\mathrm{Tetrofosmin}$ \\
Myocardial perfusion: ${ }^{99 \mathrm{~m}} \mathrm{Tc}-\mathrm{MIBI}$ \\
Myocardial perfusion: ${ }^{201} \mathrm{Tl}-\mathrm{Cl}$ \\
Tumor: ${ }^{18} \mathrm{~F}-\mathrm{FDG}$ (in-house-produced) \\
Tumor: ${ }^{18} \mathrm{~F}-\mathrm{FDG}$ (delivery)
\end{tabular}

representative diagnostic nuclear medicine examinations in Japan. More than half of the facilities were within the range of $25 \%$. In addition, more than $90 \%$ of the facilities were within the range of $50 \%$. In particular, the percentage of facilities was greater than $95 \%$ in the range of $50 \%$ in representative diagnostic nuclear medicine procedures except for the ${ }^{99 \mathrm{~m}} \mathrm{Tc}-\mathrm{Tetrofosmin}$ (myocardial perfusion scintigraphy) and ${ }^{201} \mathrm{Tl}-\mathrm{Cl}$ (myocardial perfusion scintigraphy). Our findings indicate that the administered radioactivity for diagnostic nuclear medicine has been in convergence zones in Japan.

Essentially, optimization of the dose by DRL is performed at each facility, and is believed to lead to optimization in the whole country or region. However, nuclear medicine facilities have a strong tendency to adhere to the texts and guidelines in Japan. Therefore, in the optimization of radiopharmaceutical doses in Japan, a greater role of societies and organizations or experts is needed. As the finding of this study shows and the current state of Japan, to optimize radiopharmaceutical doses, Achievable Doses (ADs) $[10,12]$ might be useful, too.

\section{Development of Japan DRLs}

Based on the results of this study, a draft of Japan DRLs was prepared by the JSNM radiological protection committee.

Subsequently, it was approved by the JSNM board of directors, board of directors of the societies and organizations that performed the collaboration investigation, 
J-RIME general meeting and J-RIME constituent bodies, respectively, and Japan DRLs were officially published on June 7, 2015 [34].

\section{Limitation}

Although the actual administered radioactivity doses to a standard body weight patient were obtained, the weight of the patients was not specified. It is necessary to pay attention to determine doses for DRLs when the standard body weight is different, because it is likely that the standard weight differs between Westerners and Asians.

\section{Conclusions}

For the first time a nationwide survey by nuclear medicinerelated societies and organizations for the development of the Japanese DRLs of nuclear medicine was conducted in Japan. This study demonstrated that the administered radioactivity in diagnostic nuclear medicine in Japan has been in the convergence zone. Nuclear medicine facilities in Japan show a strong tendency to adhere to the package insert, texts and guidelines. Furthermore, the Japan administered radioactivities were within the range of variation of the EU and the SNMMI administration radioactivities. Whether nuclear facilities can optimize the dose, or whether this is required, depends on the role of the academic societies and experts.

Acknowledgments This study was performed with financial support from the Japanese Society of Nuclear Medicine (JSNM). This study was carried out by JSNM, JSNMT, Japanese Society of Radiological Technology and JART. We would like to sincerely thank everyone in the nuclear medicine facilities who responded to and with this survey. Prof. Fumio Shishido, a committee member of the Japanese Radiological Society, supported the preparation of Japan DRLs in Nuclear Medicine. Part of this study was presented at JSNM/JSNMT Joint Symposium, the 55th Annual Meeting of the JSNM on September 14, 2015.

\section{References}

1. International Commission on Radiological Protection (ICRP). The 2007 Recommendations of the International Commission on Radiological Protection. ICRP Publication 103. Ann ICRP. 2007;37(2-4).

2. International Commission on Radiological Protection (ICRP). Radiological protection in medicine. ICRP Publication 105. Ann ICRP. 2007;37(6).

3. International Commission on Radiological Protection (ICRP). Radiological protection and safety in medicine. ICRP Publication 73. Ann ICRP. 1996;26(2).

4. International Atomic Energy Agency (IAEA). International basic safety standards for protection against ionizing radiation and for the safety of radiation sources, IAEA Safety Series No. 115. 1996.
5. Communication from the Commission concerning the implementation of Council Directive 96/29/Euratom of 13 May 1996 laying down basic safety standards for the protection of the health of the workers and the general public against the dangers arising from ionising radiation. http://eur-lex.europa.eu/legal-content/ EN/NOT/?uri=CELEX:51998DC0087. Accessed 23 Dec 2015.

6. European Commission. Radiation protection 109. Guidance on diagnostic reference levels (DRLs) for medical exposures. Luxembourg: OOPEC; 1999.

7. Mettler FAJ, Huda W, Yoshizumi TT, Mahesh M. Effective doses in radiology and diagnostic nuclear medicine: a catalog. Radiology. 2008;248:254-63.

8. Mettler FAJ, Bhargavan M, Faulkner K, Gilley DB, Gray JE, Ibbott GS, et al. Radiologic and nuclear medicine studies in the United States and worldwide: frequency, radiation dose, and comparison with other radiation sources-1950-2007. Radiology. 2009;253:520-31.

9. European Commission. DDM2 project report part 2: diagnostic reference levels (DRLs) in Europe. 2010.

10. National Council on Radiation Protection and Measurements. Reference levels and achievable doses in medical and dental imaging: recommendations for the United States. NCRP Report No. 172. Bethesda: National Council on Radiation Protection and Measurements. 2012.

11. Roch P, Aubert B. French diagnostic reference levels in diagnostic radiology, computed tomography and nuclear medicine: 2004-2008 review. Radiat Prot Dosim. 2013;154:52-75.

12. Alessio AM, Farrell MB, Fahey FH. Role of reference levels in nuclear medicine: a report of the SNMMI Dose Optimization Task Force. J Nucl Med. 2015;56:1960-4.

13. Committee for evaluation of proper use of radiopharmaceuticals, Japanese Society of Nuclear Medicine. Development of guideline for proper use of radiopharmaceuticals. Contract research of related academic society on trial project implementation for promotion of proper use of radiopharmaceuticals by Ministry of Health, Labour and Welfare 2001-2002. 2002. www.jsnm.org/files/pdf/guideline/ iyakuhin_gaidorain.pdf. Accessed 22 Dec 2015.

14. A new text book of clinical nuclear medicine. 3rd ed. Kanehara \& Co., Ltd; 1999.

15. The Japanese Society of Radiological Technology and the Japan Association of Radiological Technologists, Medical exposure guideline committee. Medical exposure guideline (reduction target dose) for patients. J JART. 2000;47:1694-750 (in Japanese).

16. Watanabe H. Medical exposure guideline 2006 (6; nuclear medicine) (reduction target dose in radiation practice). J JART. 2007;54:29-42 (in Japanese).

17. Takahashi Y, Ono K, Kikuchi K, Saito K, Takase T, Morozumi K. Radiopharmaceutical administered doses for nuclear medicine. J JART. 2013;60:359-67 (in Japanese).

18. Piepsz A, Hahn K, Roca I, Ciofetta G, Toth G, Gordon I, et al. A radiopharmaceuticals schedule for imaging in paediatrics. Paediatric Task Group European Association Nuclear Medicine. Eur J Nucl Med. 1990;17(3-4):127-9.

19. Smith T, Gordon I. An update of radiopharmaceutical schedules in children. Nucl Med Commun. 1998;19:1023-36.

20. Jacobs F, Thierens H, Piepsz A, Bacher K, Van de Wiele C, Ham $\mathrm{H}$, et al. Optimised tracer-dependent dosage cards to obtain weight-independent effective doses. Eur J Nucl Med Mol Imaging. 2004;32:581-8.

21. Lassmann M, Biassoni L, Monsieurs M, Franzius C, Jacobs F. The new EANM paediatric dosage card. Eur J Nucl Med Mol Imaging. 2007;34:769-98.

22. Treves ST, Davis RT, Fahey FH. Administrated radiopharmaceutical doses in children: a survey of 13 pediatric hospitals in North America. J Nucl Med. 2008;49:1024-2027. 
23. Gelfand MJ, Parisi MT, Treves ST. Pediatric radiopharmaceutical administered doses: 2010 North American consensus guidelines. J Nucl Med. 2011;52:318-22.

24. Treves ST, Parisi MT, Gelfand MJ. Pediatric radiopharmaceutical doses: new guidelines. Radiology. 2011;261:347-9.

25. Fahey FH, Treves ST, Adelstein SJ. Minimizing and communicating radiation risk in pediatric nuclear medicine. $\mathrm{J}$ Nucl Med. 2011;52:1240-51.

26. Zanzonico P. Virtual reality for dose optimization in pediatric nuclear medicine: better than the real thing. $J$ Nucl Med. 2011;52:1845-7.

27. Koizumi K, Masaki H, Matsuda H, Uchiyama M, Okuno M, Oguma E, et al. Japanese consensus guidelines for pediatric nuclear medicine Part 1: pediatric radiopharmaceutical administered doses (JSNM pediatric dosage card). Part 2: Technical considerations for pediatric nuclear medicine imaging procedures. Ann Nucl Med. 2014;28:498-503.

28. Japan Network for Research and Information on Medical Exposures (J-RIME). Newsletter No. 1. 2011. http://www.radher.jp/JRIME/rimelite/rimeliteNo.1.pdf. Accessed 22 Dec 2015.

29. The Japanese Society of Nuclear Medicine. FDG-PET PET/CT clinical practice guideline. 2012. http://www.jsnm.org/files/pdf/ guideline/2012/fdgpet_guideline2012_120912.pdf. Accessed 23 Dec 2015 (in Japanese).
30. Donohoe KJ, Brown ML, Collier BD, Carretta RF, Henkin RE, O'Mara RE, et al. Society of nuclear medicine procedure guideline for bone scintigraphy. 2003. http://snmmi.files.cmsplus.com/docs/pg_ch34_0403.pdf. Accessed 10 Jan 2016.

31. Donohoe KJ, Agrawal G, Frey KA, Gerbaudo VH, Mariani G, Nagel JS, et al. SNM practice guideline for brain death scintigraphy 2.0. 2012. http://snmmi.files.cms-plus.com/docs/Brain_ Death_Scintigraphy_V2.0_Final_Draft_for_Approval.pdf. Accessed 10 Jan 2016.

32. Strauss HW, Miller DD, Wittry MD, Cerqueira MD, Garcia EV, Iskandrian AS, et al. Procedure guideline for myocardial perfusion imaging 3.3. 2008. http://snmmi.files.cms-plus.com/docs/ Myocardial\%20Perfusion\%20Imaging\%203.3.pdf. Accessed 10 Jan 2016.

33. Delbeke D, Coleman RE, Guiberteau MJ, Brown ML, Royal HD, Siegel BA, et al. Procedure guideline for tumor imaging with ${ }^{18} \mathrm{~F}$ FDG PET/CT 1.0*. 2006. http://snmmi.files.cms-plus.com/docs/ jnm30551_online.pdf. Accessed 10 Jan 2016.

34. Japan Network for Research and Information on Medical Exposures (J-RIME). Diagnostic reference levels based on latest surveys in Japan-Japan DRLs 2015. 2015. http://www.radher.jp/JRIME/report/DRLhoukokusyoEng.pdf. Accessed 22 Dec 2015. 